\title{
Worksite Weight Loss Intervention for Employees in Stressful Workplaces: A Pilot Study and Baseline Survey Indicators of Success
}

\author{
Pouran D. Faghri \\ University of Connecticut School of Medicine and Dentistry \\ Valerie B. Duffy \\ University of Connecticut - Storrs \\ Nicole R. Benson \\ University of Connecticut - Storrs \\ Martin G. Cherniack \\ University of Connecticut School of Medicine and Dentistry
}

Follow this and additional works at: https://opencommons.uconn.edu/uchcres_articles Part of the Medicine and Health Sciences Commons

\section{Recommended Citation}

Faghri, Pouran D.; Duffy, Valerie B.; Benson, Nicole R.; and Cherniack, Martin G., "Worksite Weight Loss Intervention for Employees in Stressful Workplaces: A Pilot Study and Baseline Survey Indicators of Success" (2012). UCHC Articles - Research. 101.

https://opencommons.uconn.edu/uchcres_articles/101 


\title{
Obesity \& Weight loss Therapy
}

\section{Worksite Weight Loss Intervention for Employees in Stressful Workplaces: A Pilot Study and Baseline Survey Indicators of Success}

\author{
Pouran D. Faghri'*, Valerie B. Duffy ${ }^{2}$, Nicole R. Benson ${ }^{3}$ and Martin G. Cherniack ${ }^{4}$
}

${ }^{1}$ Department of Allied Health Sciences, University of Connecticut, USA

${ }^{2}$ Department of Allied Health Sciences, University of Connecticut, USA

${ }^{3}$ Department of Allied Health Sciences, University of Connecticut, USA

${ }^{4}$ Occupational \& Environmental Medicine, University of Connecticut Health Center, USA

\begin{abstract}
Statement of problem: Correctional facilities are stressful, unhealthy and dangerous working environments, which increase the risk of chronic diseases and a shortened lifespan for employees, particularly corrections officers. The need exists for effective worksite interventions to lower chronic disease risk and improve health of correctional employees.
\end{abstract}

Objective: The primary aim was to pilot test eight-week worksite nutrition and physical activity educational intervention for correctional employees and to determine baseline indicators of weight loss success.

Methods: Twenty overweight/obese volunteer employees were recruited by convenience sampling. Educational material was tailored to baseline responses on diet and physical activity knowledge, preferences, and behaviors. Adiposity status was both self-rated by the study participants and measured by researchers. The primary indicator was change in adiposity with a goal of $3 \%$ loss in weight across the intervention.

Results: The group averaged one-pound loss per week; eleven of 20 employees lost $\geq 3 \%$ of body weight. The number of overweight/obese employees with healthy waist circumferences increased from 3 to 8 post-intervention. At baseline, employees who reached the weight loss goal were most likely to: accurately assess their level of adiposity; have lower knowledge about nutrition and healthy eating; report greater preference for discretionary-energy foods but less preference for vegetables; and less confidence in changing their physical activity behaviors.

Conclusions: The intervention resulted in clinically meaningful, short-term weight loss among employees in stressful workplaces. Simple baseline survey-assessment defined employees who reported room to change their dietary and physical activity patterns as well as an accurate realization of their level of excessive adiposity.

Keywords: Obesity; Worksite; Correctional officers; Tailored intervention

\section{Introduction}

Correctional officers must cope with a variety of stressors within and outside of their institutional roles [1]. Correctional institutions are high-stress workplaces due to hierarchal organization, rotating work shifts, irregular meal schedules, and risks to personal safety during violent emergencies [2-4]. Much of the research on the health of workers in hazardous duty services (e.g., police officers, civil servants, and correctional officers) has identified a relationship between the work environment and stress [5-12]. For example, Chandola et al. [5] reported an association between chronic work stress, elevated cortisol level, and coronary heart disease among a large cohort of civil servants. Increased stress and depression also can lead to dis inhibited and binge eating [13], which increases risk of excessive adiposity.

Smoking, poor eating habits and inactivity also challenge the health of correctional officers. From our experience in northeastern United States, correctional officers exit the training academy physically fit, having passed the Cooper Institute Fitness Standards [14]. Yet, most exceed recommended weight norms within 5 years on the job due to lack of regular physical conditioning and unhealthy food environments in correctional facilities [15]. Increased stress and related behavioral risks have been attributed to the overwhelming number of overweight and obese correctional officers [4], increasing risks for coronary heart disease, hypertension, and diabetes [4,16-18].

Health promotion and public health advocates have identified the workplace as a promising setting for addressing excessive adiposity and chronic disease risk [17]. Evidence from best practices recommends that weight management interventions should include health professional-facilitated education and tailored feedback, a work environment that supports behavior changes, and employee involvement in the intervention [19,20]. Success in weight loss programs has been attributed to improvements in the participant's level of self-efficacy and confidence in changing dietary and physical activity behaviors [21] across relatively short 8-week [22] and longer 18-month [23] interventions. Traditional workplace health promotion programs typically use "one size fits all" approaches, which may be incongruent with the job conditions (demanding work schedule, inflexibility, and lack of control) and organizational hierarchy of correctional institutions. Tailoring a weight loss intervention to participant's level of knowledge, self-efficacy and extant workplace barriers, may empower correctional officers toward achieving and maintaining a healthy weight by counteracting the potential negative influences of work environment, job characteristics, and lifestyle [24].

*Corresponding author: Pouran D. Faghri, MD, MS, FACSM, Department of Allied Health Sciences, University of Connecticut, 358 Mansfield Road, U-2101, Storrs, CT 06269, USA, Tel: 860.486.0018; Fax: 860.486.5375; E-mail: pouran.faghri@uconn.edu

Received January 23, 2012; Accepted March 23, 2012; Published March 26 2012

Citation: Faghri PD, Duffy VB, Benson NR, Cherniack MG (2012) Worksite Weight Loss Intervention for Employees in Stressful Workplaces: A Pilot Study and Baseline Survey Indicators of Success. J Obes Weig los Ther 2:121. doi:10.4172/2165904.1000121

Copyright: @ 2012 Faghri PD, et al. This is an open-access article distributed under the terms of the Creative Commons Attribution License, which permits unrestricted use, distribution, and reproduction in any medium, provided the original author and source are credited. 
The purpose of this pilot study was to evaluate the effectiveness of a worksite nutrition education program in achieving weight loss through healthy behaviors for overweight/obese employees in stressful workplaces (i.e., correctional employees). The intervention was tailored to the employee's baseline survey responses on nutrition knowledge, exercise behaviors, confidence in changing behaviors, and preference for foods and exercise. The ability for these baseline responses to explain differences in those who were successful in weight loss (goal of $\geq 3 \%$ of baseline body weight) across the intervention was tested.

\section{Materials and Methods}

\section{Study design and recruitment}

The study used an 8-week pre-post test design. A convenience sample was recruited via flyers and registration forms distributed to all employees and posted for two-weeks in the officer's mess. Due to an established partnership with the State Department of Correction, and, as a stipulation of our partnership, the study enrollment was open to all employees at the selected correctional facility. Four weeks prior to program initiation, the Program Facilitator (PF) coordinated a best approach to register participants with the warden at the correctional facility. The cooperation of the warden and correctional facility administrators was critical for successful completion of the program including recruitment and implementation via the provision of: semi-private space to complete study forms and surveys and to conduct weekly educational sessions; private space for weigh-ins; and employee's time and coverage for participation without compromise to job and facility security.

\section{Participants and procedure}

Convenience sampling was used to recruit volunteer participants who met the inclusion and exclusion criteria. Inclusion criteria were: being an employee of the correctional facility, a body mass index (BMI) of $\geq 25$, no restriction in physical activity as indicated by the Physical Activity Readiness Questionnaire [25] and a commitment to the 8-week intervention and evaluation. Twenty-seven employees volunteered for the program, and after baseline measurements, 20 participants continued for the entirety of the intervention. Attrition was attributed to employee transfer of work location.All of the participants signed an informed consent approved by the University Institutional Review Board prior to participation. At baseline and after obtaining informed consent, participants were asked to complete the surveys. Adiposity measures were completed at pre and post-intervention.

The PF measured the participant's body weight using the same digital weight scale, which was calibrated regularly. BMI was calculated from the baseline weight and self-reported height ( $\left.\mathrm{wt} / \mathrm{ht}^{2}\right)$. Using a non-stretchable tape measure, waist circumference was measured around the smallest area below the rib cage and at the level of the top of the hip. Hip circumference was measured around the widest area of the hips. Perceived body size was estimated from the Stunkard Figure Rating Scale [26]. Participants identified their body size using the scale's body type pictograms to assess self-awareness of adiposity and discrepancy between measured and self-reported adiposity. Previous work in a worksite wellness program suggeststhat individuals are more willing to list a weight category than to report their actual weight [27].

Table 1 shows the characteristics of the participants. The study sample was slightly older than the overall facility employees (average age 42.5 years) and the average age for females (51.6 years) exceeded that for males ( 43.3 years, $\mathrm{p}<0.05$ ). According to the pre-intervention

\begin{tabular}{|c|c|c|}
\hline \multicolumn{3}{|c|}{ Baseline Characteristics } \\
\hline \multirow{2}{*}{ Gender } & Male & 11 \\
\hline & Female & 9 \\
\hline Age & Years \pm St. Dev. (Range: 19-72 yrs) & $47.1 \pm 8.8$ \\
\hline $\begin{array}{l}\text { Anthropometrics } \\
\text { Male }\end{array}$ & $\begin{array}{l}\text { Weight: Pounds } \pm \text { St. Dev. } \\
\text { BMl: Kg/cm² } \pm \text { St. Dev. } \\
\text { Waist: Inch } \pm \text { St. Dev. }\end{array}$ & $\begin{array}{l}262 \pm 6.2 \\
36.6 \pm 6.7 \\
46.6 \pm 6.9\end{array}$ \\
\hline $\begin{array}{l}\text { Anthropometrics } \\
\text { Female }\end{array}$ & $\begin{array}{l}\text { Weight: Pounds } \pm \text { St. Dev. } \\
\text { BMl: Kg/cm² } \pm \text { St. Dev. } \\
\text { Waist: Inch } \pm \text { St. Dev. }\end{array}$ & $\begin{array}{l}170 \pm 21.1 \\
29.6 \pm 4.4 \\
35.8 \pm 2.6\end{array}$ \\
\hline \multirow{3}{*}{ Race } & Hispanic (Answered Yes) & 2 \\
\hline & White & 15 \\
\hline & African American / Black & 3 \\
\hline
\end{tabular}

Table 1: Baseline Characteristics of Worksite Employees.

BMI, 7 participants (35\%) were overweight (25-29), 6 (30\%) had class I obesity (30-34.9), 5 (25\%) had class II obesity (35-39.9) and $2(10 \%)$ had class III or extreme obesity $(\geq 40)[28]$. The males at baseline had significantly higher BMIs than did the females $(p=0.01)$, and were skewed toward being obese. Higher risk waist circumferences were seen for all of the males ( $>40$ inches) and for 6 of the 9 women $(<35$ inches).

\section{Surveys on nutrition knowledge, attitudes and behaviors toward food and physical activity}

Following previously validated protocols [29-31], participants completed 3-section nutrition and physical activity questionnaire to assess knowledge, usual dietary and exercise habits, as well as levels of confidence and barriers to changing eating and exercise behaviors. The first section contained ten multiple-choice or multiple component questions, adopted from the Hawkes and Nowak nutrition knowledge questionnaire [25], which asked whether foods were low in cholesterol, fat, or fiber. One point was given for correct answers and zero points for incorrect or "not sure" answers, for a total maximal score of 38 points. The second section contained 26 multiple choice and openended questions to identify participant's eating and exercise habits at the workplace $[29,30]$. The third section assessed the participant's motivation and self-efficacy regarding a regular exercise program [32,33].

Participants completed a separate survey asking their level of liking/ disliking for foods and physical activity. Previous research has shown that reported preference for foods serves as a proxy of habitual dietary intake [27,34]. The survey contained 62 foods/beverages, 7 physical activity items, and 7 pleasurable (e.g., jumping into a pool on a hot day) and unpleasurable (e.g., glare of headlights) items on the hedonic general Labeled Magnitude Scale. The bidirectional scale has labels spaced to give the scale ratio properties: strongest liking/disliking is located at the ends $( \pm 100)$, neutral in the middle $(0)$, and intermediate labels of weakly $( \pm 6)$, moderately $( \pm 17)$, strongly $( \pm 35)$, and very strongly ( \pm 54$)$ like/dislike. The non-food items generalize the hedonic scale, increasing the ability to compare ratings across individuals [35] and providing insight to motivation for eating (e.g., food hedonism) [27,34]. Individual items were conceptually grouped by foods, physical activities, and non-foods.

\section{Intervention period}

The study group participated in eight, 1-hour weekly educational sessions lead by the PF who had formal training in health promotion and health education, was certified by a major insurance corporation 
on their workplace weight loss programs, and had previous experience implementing health program interventions at correctional facilities. Four weekly education sessions (two per week, one in the morning, and one in the afternoon to reach all shifts) were held to provide employees with maximum opportunity to attend sessions convenient to their work and shift schedules. They were discouraged from attending more than 1 session per week. During the first week, the PF met with the 20 participants, who then created seven teams of 2-5 members each. The team model was consistent with the small group nature of corrections work. Weekly meetings were scheduled between the PF and each team to discuss and provide nutrition and weight loss information. The participants were required to attend at least in 6 of the 8 weekly sessions and monitored their progress through food and activity logs.

\section{Tailored weight loss intervention}

The focus of the intervention was to promote knowledge and attitudes conducive to improving or maintaining positive dietary and physical activity practices for healthy behaviors and weight loss, following the US Department of Agriculture's Food Guide Pyramid and the US Department of Health and Human Services' National Cholesterol Program Guidelines. The general topic areas are shown in Table 2.

Although the session topics were the same for all teams, the PF utilized the baseline survey responses to tailor the educational sessions and handouts for nutrition messages, emphasizing portion control, flexible restraint, planned indulgences and a positive relationship with food. This approach is consistent with most of the research identifying barriers to weight loss including perceived taste, lack of convenience/ time, high cost, confusing advertising, and lack of knowledge of actual food intake and dietary recommendations [36-39]. During educational sessions, the PF discussed issues regarding energy balance, portion size and calorie counting. In terms of nutrition knowledge for example, the instruction addressed that 15 of 20 participants incorrectly answered questions pertaining to fat and cholesterol contents of foods as well as fruit and vegetable intake recommendations. Further educational tailoring was specific to environmental constrains of the correctional facility (e.g., planning healthy meal options for extended shift hours and avoiding overeating energy dense, low-nutrient quality foods during double shifts). For each session, a detailed outline of the didactic materials was presented to the participants.

\section{Data analysis}

Changes in adiposity across the intervention were tested with

\begin{tabular}{|c|c|}
\hline Session & Lessons \\
\hline 1 & $\begin{array}{l}\text { Introduction to My Pyramid, Caloric Balance, Your Healthy Weight, } \\
\text { and Portion Sizes }\end{array}$ \\
\hline 2 & $\begin{array}{l}\text { Benefits to Exercise, Create an Exercise Plan, Learn How to Move } \\
\text { Everyday }\end{array}$ \\
\hline 3 & $\begin{array}{l}\text { Sample Meal Plans, Learn How to Read Nutrition Labels, Healthy } \\
\text { Snacks, Plan-Ahead Meals }\end{array}$ \\
\hline 4 & $\begin{array}{l}\text { Create a Healthy Environment at Home and Work, Hunger Scale, } \\
\text { Identifying Triggers }\end{array}$ \\
\hline 5 & $\begin{array}{l}\text { Prioritize a Healthy Lifestyle, Finding Your Support System, Making } \\
\text { Time to Exercise, On-the-go Activities }\end{array}$ \\
\hline 6 & $\begin{array}{l}\text { Strategies to Healthy Eating While Dining Out, Ingredient } \\
\text { substitutions, Key Components to a Healthy Diet }\end{array}$ \\
\hline 7 & Identify Signs and Sources of Stress, Problem Solving \\
\hline 8 & Keys to Success, Positive Self-Talk \\
\hline
\end{tabular}

Table 2: Lessons for intervention sessions.

\section{Distribution of weight change across the 8-week intervention}

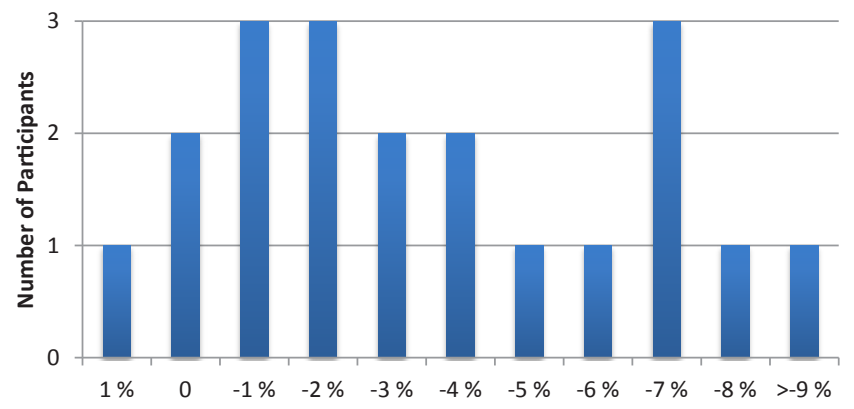

Figure 1: Individual participant's percentage weight loss following 8-weeks intervention.

\begin{tabular}{|c|c|c|c|c|c|c|c|}
\hline \multirow{2}{*}{\multicolumn{2}{|c|}{ Categories* }} & \multicolumn{3}{|c|}{ Baseline } & \multicolumn{3}{|c|}{ Post Intervention } \\
\hline & & \multirow{2}{*}{$\begin{array}{l}\text { Total } \\
0\end{array}$} & \multirow{2}{*}{$\begin{array}{l}\text { Waist } \\
\text { Normal }\end{array}$} & \multirow{2}{*}{$\begin{array}{l}\text { Waist } \\
\text { Elevated }\end{array}$} & \multirow{2}{*}{$\begin{array}{l}\text { Total } \\
1\end{array}$} & \multirow{2}{*}{$\begin{array}{l}\text { Waist } \\
\text { Normal }\end{array}$} & \multirow{2}{*}{\begin{tabular}{|l} 
Waist \\
Elevated \\
1
\end{tabular}} \\
\hline Normal & $(18.5<\mathrm{BMI}<25)$ & & & & & & \\
\hline Overweight & $(25<\mathrm{BMI}<30)$ & 7 & 3 & 4 & 8 & 7 & 1 \\
\hline Obese I & $(30<\mathrm{BMI}<35)$ & 6 & & 6 & 6 & 1 & 5 \\
\hline Obese II & $(35<\mathrm{BMI}<40)$ & 5 & & 5 & 3 & & 3 \\
\hline Obese III & $(40 \leq \mathrm{BMI})$ & 2 & & 2 & 2 & & 2 \\
\hline
\end{tabular}

Table 3: Participants BMI/Waist-circumference classification.

${ }^{*} \mathrm{CDC}$ classifications including waist circumference normal as $<35$ in. for females and <40 in. for males; waist elevated above these cutoffs (www.nhlbi.nih.gov/ guidelines/obesity/prctgd_c.pdf)

paired t-tests. Differences in baseline survey responses and associations with change in adiposity were tested for central tendency (independent t-test) and distribution with Chi Square Test of Association or the Fisher Exact Probability Test (two-tailed). The criterion for significance was $\mathrm{p} \leq 0.05$.

\section{Results}

\section{Change in adiposity across the intervention and associations with perceived adiposity}

From pre to post intervention, there were significant losses in weight, BMI and waist circumference in both males and females $(p<0.01)$. The average weight loss at week 8 was $8.3 \mathrm{lbs}$, ranging from $26.2 \mathrm{lbs}$ lost to 1.8 pounds gained, which corresponds to an average of $3.6 \%$ weight lost across all participants (Figure 1). The average BMI decreased from 33.5 at baseline to 32.3 at the final week. In comparison with females, males achieved significantly greater loss of weight and BMI $(\mathrm{p}<0.05)$, but not greater percentage of weight loss. The average reduction in waist circumference was 1.4 inches, ranging from 6.6 inches lost to 1.2 inches gained.The number of participants with normal waist circumference (lower disease risk, according to the CDC BMI/ Waist circumference classification) increased by two and half fold, from 3 or $15 \%$ at baseline to 8 or $40 \%$ at post intervention (Table 3 ). Although there was no gender difference in loss of waist circumference, females showed significantly greater variance in circumference lost $(+1.2$ to -6.6 inches) than did males $(+0.5$ to -4 inches, $\mathrm{p}<0.05)$.

Comparing measured to perceived adiposity status, 14 individuals (70\%) showed concordance between perceived and measured BMI categories (Table 4). None of the individuals perceived that they 


\begin{tabular}{|c|c|c|c|}
\hline & \multicolumn{3}{|c|}{ Perceived Body Size } \\
\hline BMI & Normal & Overweight & Obese \\
\hline Normal & 0 & 0 & 0 \\
\hline Overweight & 0 & 6 & 1 \\
\hline Obese I & 0 & 3 & 3 \\
\hline Obese II & 0 & 2 & \\
\hline Obese III & 0 & 0 & 2 \\
\hline
\end{tabular}

\section{Men}
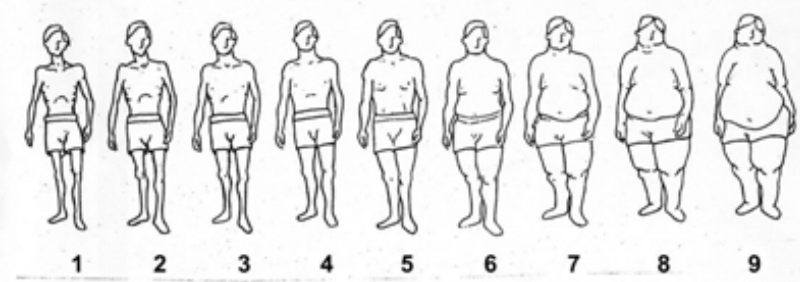

Women

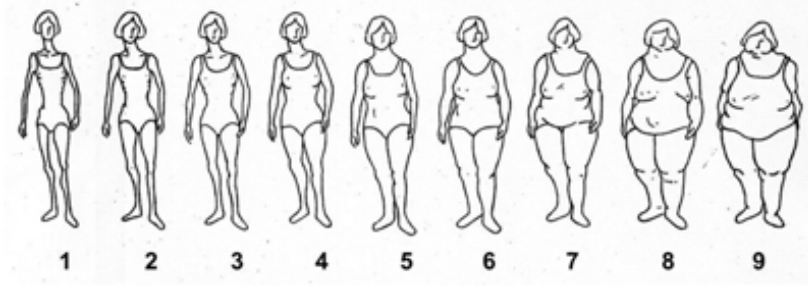

Table 4: The joint distribution between measured CDC BMI categories and perceived body size based on the Stunkard figures (1=very thin, 2-3 normal, 4-6 overweight, 7-9 obese) showing concordance (shaded) and discordance (un-shaded) at baseline.

were a normal weight. The 6 individuals $(30 \%)$ who were discordant in perceived vs. measured adiposity (Table 4) achieved less than $3 \%$ weight loss from pre to post intervention (Fisher Exact Probability Test, $\mathrm{p}<0.05)$.

\section{Baseline nutrition survey responses and associations with intervention weight loss}

The nutrition knowledge score at baseline ranged from 11 to 29, with an average score $(20.3 \pm 4.5)$ equal to half of the items being answered incorrectly, and did not differ significantly between males and females. There was no significant relationship between nutrition knowledge and either baseline adiposity or waist circumference. However, employees with below average knowledge scores showed more success in the weight loss intervention they tended to be distributed in the greater than $3 \%$ weight loss category than those with above average baseline knowledge scores (Fisher Exact Probability Test, $\mathrm{p}=0.07$ ).

Fruits, vegetables, whole grain, and milk products were ranked as less preferred at baseline than were high-fat food groups (Table 5). Participants who lost $3 \%$ of their baseline weight or more across the intervention (versus those who lost $<3 \%$ ) reported less healthy dietary preferences at baseline. According to Fisher's Exact Probability Testing, the more successful weight loss group fell into higher liking categories at baseline for sweets and alcoholic beverages $(\mathrm{p}<0.05)$ but tended to fall into lower liking group at baseline for vegetables $(\mathrm{p}=0.06)$. Eleven participants (55\%) were classified as having high food interest (food groups were ranked as more liked than pleasurable non-food items), while eight participants (45\%) were classified as having lower food interest (food groups were ranked as less liked than pleasurable nonfood items). High food interest individuals had significantly higher baseline BMIs ( $\mathrm{p}<0.05)$, yet did not differ significantly in the amount of weight/adiposity lost from pre to post intervention.

\section{Baseline physical activity survey responses and associations with intervention weight loss}

From the survey reports at baseline, 15 participants (75\%) reported no activity or less than three times of recommended physical activity per week [40]. Males and females did not differ in level of physical inactivity and higher age was not associated with greater inactivity (none or less than once/week). Participants who reported inactivity did not differ significantly in baseline BMI or waist circumference, central tendency or distribution, from those who reported physical activity.

Across all participants, the average hedonic rating for physical activity was just above moderately liked (average $=22.1 \pm 27.5$ St. Dev.), with large variation $(<$ moderately disliked to $>$ strongly liked) that did not differ significantly between males or females or by age. Reported liking for physical activity did not differ significantly between those who were inactive versus active, suggesting other barriers to physical activity than level of liking (see below). The relationship between liking for physical activity and adiposity measures was not linear. Those who were heaviest $(\mathrm{BMI} \geq 35)$ reported greatest level of liking for physical activity.

From the survey responses, $85 \%$ of participants ( 17 of 20 ) reported no time, not enough energy, or laziness as barriers to physical activity, with none reporting health or injury worry as a barrier. Reported confidence in physical activity across the 11 items was varied, ranging from low $($ score $<2)$ to high $($ score $=5)$ confidence. The relationship between reported physical activity and physical activity confidence was $\mathrm{j}$-shaped: those with highest confidence either reported being inactive or being highly activity. Individuals who lost $>1$ inch in waist circumference across the intervention had lower baseline confidence scores than did individuals who lost $\leq 1$ inch $(\mathrm{p}<0.05)$. Change in BMI was not related significantly to baseline confidence scores.

\section{Discussion}

The present pilot study evaluated 8-week worksite weight loss intervention for correctional employees, supplemented with nutrition and physical activity survey assessments that were used to tailor the messages and educational intervention as well as characteristics of employees who were most successful in losing weight. The average pre-post intervention loss of weight and adiposity was significant and reached clinical significance ( $>3 \%$ weight loss).Participants who had less healthy dietary behaviors at baseline, measured by less healthy dietary preferences and lower nutrition knowledge, were most responsive to the intervention as measured by percentage weight loss. The reported level of physical activity at baseline was unrelated to the level of weight loss, however, those who were less confident about their physical 
activity at baseline showed greater losses of waist circumference.

Losing $3-5 \%$ of body weight can delay or prevent chronic conditions related to obesity [41,42]. Over the 8-week program, participants lost an average of $8.3 \mathrm{lbs}$, which is consistent with the CDC recommendations of a slow and steady weight loss of 1-2 pounds per week for an overweight or obese individual. Similar results have been reported in other worksite weight loss programs $[3,16,43]$. There is a dispute over what is the best approach to measure effectiveness of weight loss interventions [44]. Our pilot study found value in utilizing weight (\% weight loss) and waist circumference as both measures documented improvements in adiposity across the intervention in men and women. Studies have reported that those who have lower waist circumference, despite being BMI-categorized as overweight or obese, have lower chronic disease risk $[45,46]$. In our study, the average reduction in waist circumference was 1.4 inches and the number of individuals with elevated and at-risk waist circumferences (i.e., $>40$ inches for males, $>35$ inches for females) was reduced from 17 to 12 individuals at the completion of the intervention (Table 3 ).

The present pilot study utilized Stunkard's Figure Rating Scale (FRS) [47] to evaluate the participant's perceived adiposity, its relationship to measured adiposity, and whether it was informative on weight loss success. Utilizing FRS might more suitable than direct weight measurement at workplaces to prevent stigmatization and threat to self-esteem at being weighed at work. For example, correction officers have an authoritative role at work and in charge of inmates. In such environment, direct measurement of obesity and being labeled as "obese" may not be welcomed. There was reasonable agreement between the participants' perceived level of adiposity and measured BMI classification (Table 4). Furthermore, those who accurately reported their category on the FRS were also more successful in losing weight. Lynch et al. [48] found that women, who correctly identified with the obese character on the FRS and had measured obesity, were less likely to gain weight over time across a longitudinal study. If

\begin{tabular}{|l|l|l|}
\hline $\begin{array}{l}\text { Rank } \\
\text { (least to most } \\
\text { preferred) }\end{array}$ & Food Group & Mean Rating \pm StdDev* \\
\hline 15 & Unpleasurable Items & $-52.5 \pm 26.9$ \\
\hline 14 & Alcohol & $-5.7 \pm 44.2$ \\
\hline 13 & Spicy Foods & $10.5 \pm 44.4$ \\
\hline 12 & Milk Products & $10.7 \pm 27.7$ \\
\hline 11 & Starchy Foods & $19.9 \pm 27.8$ \\
\hline 10 & Whole Grains & $20.8 \pm 21.4$ \\
\hline 9 & Physical Activity & $22.1 \pm 27.6$ \\
\hline 8 & Vegetables & $22.6 \pm 24.0$ \\
\hline 7 & Fruit & $28.3 \pm 25.7$ \\
\hline 6 & Sweets & $29.2 \pm 21.8$ \\
\hline 5 & High-fat snacks \& Condiments & $31.0 \pm 13.9$ \\
\hline 4 & High-fat meats & $32.7 \pm 23.2$ \\
\hline 3 & Sitting, watching TV & $45.2 \pm 27.1$ \\
\hline 2 & Low-fat meats & $46.0 \pm 28.1$ \\
\hline 1 & Pleasurable Items & $53.7 \pm 18.7$ \\
\hline
\end{tabular}

Table 5: Average hedonic ratings of groups at baseline range from disliked unpleasurable items.

* Neutral in the middle (0), and intermediate labels of weakly $( \pm 6)$, moderately $( \pm 17)$, strongly $( \pm 35)$, and very strongly $( \pm 54)$ like/dislike, strongest liking/disliking $( \pm 100)$. inaccurate self-perception is a barrier to effective weight loss, the use of instruments like the FRS may have utility in workplace weight loss programs [49].

The present study tailored the nutrition and educational information to the participant's knowledge and skills. Furthermore, as part of the customization, we aimed to increase confidence in making positive behavior changes within the environmental constrains of the correctional facility. Our results indicated that participants who had below the average knowledge scores were more likely to achieve a clinically significant weight loss. The baseline survey response suggested that the study group lacked the nutrition knowledge necessary to make healthy food choices. Our findings are consistent with others that have shown that educational approaches focused on nutrition and physical activity can effectively increase healthy behaviors, achieve clinically significant weight loss [50] and improve blood pressure during the intervention and at the one-year follow-up[17].

Another noteworthy approachin our study was assessment of participant's usual food intake via a reported food preferences in order to tailor nutritional messages that promote lower energy and more nutrient dense intakes. The Food Liking Survey provides a rapid method of measuring habitual intake that maybe less prone to reporting bias (e.g., underreporting intake of less healthy foods). Recall of liking is cognitively simpler than recall of specific intake behaviors [51] and, thus, liking surveys take less time to complete than other dietary assessments. Individuals tend to eat what they like and avoid what they do not and reported food likes/dislikes is associated with diet-related health indices like adiposity and blood pressure [27,34]. Consistent with these findings, the present study found that participants who had high level of food interest were heavier than those with lower level of food interest. We also found that participants, whose pre-intervention food preference patterns likely associate with energy overconsumption, were more successful at losing weight across the intervention. These participants may have a readiness to change dietary behaviors, accurately reporting areas in their diet that can be changed to lower energy intakes. Based on individual's likes and/or dislikes, sustainable dietary recommendations can be provided to individuals who are ready to make the changes necessary to lose weight $[51,52]$. Thus, food-liking surveys could offer a feasible and valid method for evaluating dietary changes across weight loss interventions.

Many participants reported low energy levels and/or lack of time as the reason(s) for not participating in physical activity, not because they disliked physical activity. There was a low confidence in getting up early to exercise, sticking to an exercise program after a long day at work, and exercising despite feelings of depression. Increasing knowledge regarding physical activity may translate to an increase in health selfefficacy and increased exercise behavior [53]. If work conditions and work culture discourage leisure time exercise, sustaining behavior modifications long after an intervention may require institutional, as well as individual remedies. Correctional employees would benefit from incorporating physical activity into their structured worksite, thus shifting the emphasis from individual motivation to physical and organizational changes in the workplace.

There were a number of limitations of the present study. The sample size was a primary limitation. However, this was a pilot study to evaluate both feasibility and effectiveness of a weight loss program at a corrections facility. Despite the small sample size, the study found significant changes in weight. Lack of control over job task, job rotation, and shift work, as expected, limited the ability of many correction 
employees to participate or to complete the entire program. Future programs should consider these job characteristics during planning and implementation of worksite health promotion programs.

In conclusion, there is paucity of research on workplace weight management programs for employees in stressful jobs such as correctional employees. Traditional workplace health-promoting programs may not be suitable for these unique workplaces, with hierarchical organizations, shift work, lack of job control, and very stressful and demanding work environment [12-14]. Health promotion programs in corrections need to account for social norms and these unique characteristics to ensure program success [16]. Increased stress can lead to over-eating and may increase the risk of becoming overweight/obese [17], particularly if the only foods available are high in energy and low in nutrient value. The long hours and constant overtime also leaves little time to plan healthy meal options and no opportunity for regular physical activity workouts. The increased stress levels, along with the lack of exercise and excessive eating seem to be the cause for the overwhelming number of overweight and obese correctional officers [12]. The excess weight may affect officer's response time to emergency situations and escalate health and injury risk [4,16-18].

The workplace weightloss intervention could be an effective strategy to address excessive adiposity and promote healthy lifestyle behaviors. Previous research has shown that employees, especially those most in need, are unlikely to partake in worksite weight loss interventions because they fail to address specific workplace constraints and barriers to achieving healthy lifestyles. This is the first program, to our knowledge, that reported on and showed success of a tailored weight loss intervention for correctional employees based on participant responses to simple baseline surveys on nutrition and physical activity knowledge, attitudes and behaviors. The program was delivered within the constraints of the correctional facility environment. Participants who had the lowest knowledge, confidence, and/or behaviors about healthy diet and physical activity showed the most success at losing weight across the intervention. This pilot study and previous research $[2,3]$ support that interventions which address the unique workplace demands and facilitate participation increase potential for intervention success, and maintaining healthy behaviors in the future.

\section{Acknowledgements}

This research is supported by Grant Number $1 \mathrm{U} 19 \mathrm{OH} 008857$ from the National Institute for Occupational Safety and Health as part of the Center for the Promotion of Health in the New England Workplace (CPH-NEW). This work was also supported by USDA Hatch Project CONS00827.

\section{References}

1. McCraty R, Atkinson M, Lipsenthal L, Arguelles L (2009) New Hope for Correctional Officers: An Innovative Program for Reducing Stress and Health Risks. Appl Psychophysiol Biofeedback 34: 251-272.

2. Swenson D, Waseleski D, Hartl R (2008) Shift Work and Correctional Officers: Effects and Strategies for Adjustment. J Correct Health Care 14: 299-310.

3. Winick C, Rothacker DQ, Norman RL (2002) Four Worksite Weight Loss Programs with High-Stress Occupations using a Meal Replacement Product. Occup Med (Lond) 52: 25-30.

4. Wright LN, Northrup MK (2001) Examining the Health Risks for Corrections Professionals. Corrections Today 63: 106-108.

5. Chandola T, Britton A, Brunner E, Hemingway H, Malik M, et al. (2008) Work Stress and Coronary Heart Disease: What are the Mechanisms? Eur. Heart J. 29: $640-648$
6. Dignam JT, Barrera M Jr, West SG (1986) Occupational Stress, Social Support, and Burnout among Correctional Officers. Am J Community Psychol. 14: 177 193.

7. Gershon RR, Lin S, Li X (2002) Work Stress in Aging Police Officers. J Occup Environ Med 44: 160-167.

8. Keinan G, Malach-Pines A (2007) Stress and Burnout among Prison Personnel: Sources, Outcomes, and Intervention Strategies. Criminal Justice and Behavior 34: $380-398$

9. Kiely J, Hodgson G (1990) Stress in the Prison Service - The Benefits of Exercise Programs. Human Relations 43: 573-582.

10. Lasky GL, Gordon BC, Srebalus DJ (1986) Occupational stressors among federal correctional officers working in different security levels. Criminal Justice and Behavior 13: 317-327.

11. Samuelson M, Carmody J, Kabat-Zinn J, Bratt M (2007) Mindfulness-Based Stress Reduction in Massachusetts Correctional Facilities. The Prison Journal 87: 254-268.

12. Schaufeli WB, Peeters MCW (2000) Job Stress and Burnout among Correctional Officers: A Literature Review. Int J Stress Manag 7: 19-48.

13. Colles SL, Dixon JB, O'Brien PE (2008) Hunger Control and Regular Physical Activity Facilitate Weight Loss After Laparoscopic Adjustable Gastric Banding Obes. Surg. 18: 833-840.

14. The Cooper Institute (2011)

15. Kelly Cheeseman Dial, W. Wesley Johnson (2008) Working within the Walls: The Effect of Care from Coworkers on Correctional Employees. PICJ 3: 17-32.

16. French SA, Harnack LJ, Toomey TL, Hannan PJ (2007) Association between Body Weight, Physical Activity and Food Choices among Metropolitan Transit Workers. Int. J Behav Nutr Phys Act 4: 52.

17. Gemson DH, Commisso R, Fuente J, Newman J, Benson S (2008) Promoting Weight Loss and Blood Pressure Control at Work: Impact of an Education and Intervention Program. J Occup Environ Med 50: 272-281.

18. Williams AE, Vogt TM, Stevens VJ, Albright CA, Nigg CR, et al. (2007) Work, Weight, and Wellness: The 3W Program: A Worksite Obesity Prevention and Intervention Trial. Obesity (Silver Spring) 15: 16S-26S.

19. Chapman LS, American Journal of Health Promotion Inc (2003) MetaEvaluation of Worksite Health Promotion Economic Return Studies. Am J Health Prom 17: 1-10.

20. Steyn NP, Parker W, Mchiza Z, Lambert EV (2009) Nutrition Interventions in the Workplace: Evidence of Best Practice. South African Journal of Clinical Nutrition 22(3): 111-117.

21. Cochrane G (2008) Role for a Sense of Self-Worth in Weight-Loss Treatments: Helping Patients Develop Self-Efficacy. Can Fam Physician 54: 543-547.

22. Linde JA, Rothman AJ, Baldwin AS, Jeffery RW (2006) The Impact of SelfEfficacy on Behavior Change and Weight Change among Overweigh Participants in a Weight Loss Trial. Health Psychol. 25: 282-291.

23. Warziski MT, Sereika SM, Styn MA, Music E, Burke LE. (2008) Changes in SelfEfficacy and Dietary Adherence: The Impact on Weight Loss in the PREFER Study. J Behav Med 31: 81-92.

24. Dishman RK, Oldenburg B, O’Neal H, Shephard RJ (1998) Worksite Physical Activity Interventions. Am J Prev Med 15: 344-361.

25. Thomas S, Reading J, Shephard RJ (1992) Revision of the Physical Activity Readiness Questionnaire (PAR-Q). Can J Sport Sci 17: 338-345.

26. Stunkard AJ, Sørensen T, Schulsinger F (1983) Use of the Danish Adoption Register for the Study of Obesity and Thinness. Res Publ Assoc Res Nerv Ment Dis 60: 115-120.

27. Duffy VB, Hayes JE, Sullivan BS, Faghri P (2009) Surveying Food and Beverage Liking A Tool for Epidemiological Studies to Connect Chemosensation with Health Outcomes. Ann N Y Acad Sci 1170: 558-568.

28. U.S. Department of Health and Human Services, Public Health Service, 
Citation: Faghri PD, Duffy VB, Benson NR, Cherniack MG (2012) Worksite Weight Loss Intervention for Employees in Stressful Workplaces: A Pilot Study and Baseline Survey Indicators of Success. J Obes Weig los Ther 2:121. doi:10.4172/2165-904.1000121

Page 7 of 7

National Institutes of Health, National Heart, Lung, and Blood Institute, 2000 The Practical Guide Identification, Evaluation, and Treatment of Overweight and Obesity in Adults, NIH Publication.

29. Booth ML, Bauman A, Owen N, Gore CJ (1997) Physical Activity Preferences, Preferred Sources of Assistance, and Perceived Barriers to Increased Activity among Physically Inactive Australians. Prev Med 26: 131-137.

30. Clark MM, Abrams DB, Niaura RS, Eaton CA, Rossi JS (1991) Self-Efficacy in Weight Management. J Consult Clin Psychol 59: 739-744

31. Hawkes A, Nowak M (1998) A Validated Nutrition Knowledge Questionnaire for Cardiac Patients. Australian Journal of Nutrition and Dietetics 55: 21-24.

32. Washburn RA, Montoye HJ (1986) The Assessment of Physical Activity by Questionnaire. Am J Epidemiol 123: 563-576.

33. Sallis JF, Grossman RM, Pinski RB, Patterson TL, Nader PR (1988) The Development of Self-Efficacy Scales for Healthrelated Diet and Exercise Behaviors. Prev Med 3: 283-292.

34. Duffy VB, Lanier SA, Hutchins HL, Pescatello LS, Johnson MK, et al. (2007) Food preference questionnaire as a screening tool for assessing dietary risk of cardiovascular disease within health risk appraisals. J Am Diet Assoc 107 237-245.

35. Bartoshuk LM, Duffy VB, Hayes JE, Moskowitz HR, Snyder DJ (2006) Psychophysics of Sweet and Fat Perception in Obesity: Problems, Solutions and New Perspectives. Philos Trans R Soc Lond B Biol Sci 361: 1137-1148.

36. Damrosch S (1991) General Strategies for Motivating People to Change their Behavior. Nurs Clin North Am 26: 833-843.

37. Anderson AS, Cox DN, McKellar S, Reynolds J, Lean ME, et al. (1998) Take Five, a Nutrition Education Intervention to Increase Fruit and Vegetable Intakes: Impact on Attitudes Towards Dietary Change. Br J Nutr 80: 133-140.

38. Melnyk KA (1988) Barriers: A Critical Review of Recent Literature. Nurs Res 37: 196- 201

39. Kayman S (1989) Applying Theory from Social Psychology and Cognitive Behavioral Psychology to Dietary Behavior Change and Assessment. J Am Diet Assoc 89: 191-193.

40. U.S. Department of Health and Human Services, 2001, The Surgeon General's call to action to prevent and decrease overweight and obesity. U.S. Department of Health and Human Services, Public Health Service, Office of the Surgeon General. Rockville, MD.

41. Wing RR, Lang W, Wadden TA, Safford M, Knowler WC, et al. (2011) Benefits of Modest Weight Loss in Improving Cardiovascular Risk Factors in Overweight and Obese Individuals with Type 2 Diabetes. Diabetes Care 34: 1481-1486.

42. Gaesser GA, Angadi SS, Sawyer BJ (2011) Exercise and Diet, Independent of Weight Loss, Improve Cardiometabolic Risk Profile in Overweight and Obese Individuals. Phys Sportsmed 39: 87-97.

43. Pritchard JE, Nowson CA, Wark JD (1997) A Worksite Program for Overweight Middle-Aged Men Achieves Lesser Weight Loss with Exercise than with Dietary Change. J Am Diet Assoc 97: 37-42.

44. Lofgren I, Herron K, Zern T, West K, Patalay M, et al. (2004) Waist circumference is a better predictor than body mass index of coronary heart disease risk in overweight premenopausal women. J Nutr 134: 1071-1076.

45. Haffner SM, Mitchell BD, Stern MP, Hazuda HP, Patterson JK (1992) Public Health Significance of Upper Body Adiposity for Non-Insulin Dependent Diabetes Mellitus in Mexican Americans. Int J Obes Relat Metab Disord 16 177-184.

46. Zhu S, Wang Z, Heshka S, Heo M, Faith MS, et al. (2002) Waist Circumference and Obesity-Associated Risk Factors among Whites in the Third Nationa Health and Nutrition Examination Survey: Clinical Action Thresholds. Am. J. Clin. Nutr. 76(4): 743-749.

47. Cardinal TM, Kaciroti N, Lumeng JC (2006) The Figure Rating Scale as an Index of Weight Status of Women on Videotape. Obesity (Silver Spring) 14 2132-2135.

48. Lynch E, Liu K, Wei GS, Spring B, Kiefe C, et al. (2009) The relation between body size perception and change in body mass index over 13 years: the Coronary Artery Risk Development in Young Adults (CARDIA) study. Am J Epidemiol 169: 857-866.

49. Puhl RM, Brownell KD (2006) Confronting and Coping with Weight Stigma: An Investigation of Overweight and Obese Adults. Obesity 14: 1802-1815

50. Lally P, Chipperfield A, Wardle J (2008) Healthy habits: efficacy of simple advice on weight control based on a habit-formation model. Int $\mathrm{J}$ Obes 32 700-707.

51. Johnson MK, Kim JK, Risse G (1985) Do alcoholic Korsakoff's syndrome patients acquire affective reactions? J Exp Psychol Learn Mem Cogn 11: 22 36.

52. Ledikwe JH, Ello-Martin J, Pelkman CL, Birch LL, Mannino ML, et al. (2007) A reliable, valid questionnaire indicates that preference for dietary fat declines when following a reduced-fat diet. Appetite 49: 74-83.

53. Rimal RN (2001) Longitudinal Influences of Knowledge and Self-Efficacy on Exercise Behavior: Tests of a Mutual Reinforcement Model. J Health Psycho 6: 31-46.

\section{Submit your next manuscript and get advantages of OMICS Group submissions}

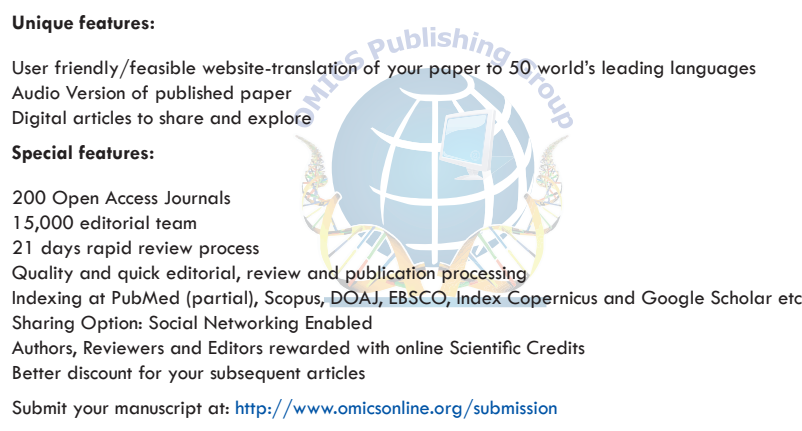

